\title{
THE ALBANIAN BRAIN DRAIN PHENOMENA AND THE BRAIN GAIN STRATEGY
}

\author{
Arta Musaraj \\ Rector of "Pavaresia" University Albania
}

\section{ABSTRACT}

Qualitative human resources remain one of the main problem of Eastern Europe and in particular Western Balkan countries. After 20 years of deep economic, political and social transformation, those countries are facing the problem of the highly qualified human resources they lost in these two decades, while in most of cases there is no a rea measurement of the weight and impact these phenomena of Brain Drain has in the quality of the work force.

Most of them are trying to set up and apply Brain Gain strategies at a national level.

The paper aims to analyze and evaluate the influence that the missing of a previous qualitative and quantitative evaluation of the Phenomena of Brain Drain in Albania, has in the successful application of the Brain Gain strategy.

The research objective will be fulfilled by analyzing the evolution of the Brain Drain phenomena, by an introduction of the Albanian characteristic and shape of Brain Drain from 1990, by analyzing the Brain Gain strategy applied in the country comparing it to a successful application. The pape analyzes factors and variables which may affect the successful application of Brain Gain in Albania while evidences the importance of stakeholder approach in objectives and aims of Brain Gain program and strategy and the use of the Balance Scorecard as a strategic management system in "brain gain" strategy set up and application in the case of Albania and those of other countries of the region as well.

\section{JEL CLASSIFICATION \& KEYWORDS}

J24 Human Resources $\square$ Brain Drain a Brain Gain Strategy Developing Countries Economic Development

\section{INTRODUCTION - Brain Drain Phenomenon today}

When it comes to education systems, most states pay attention to the future, whereas countries as Albania have to deal with problems concerning the present and the future as well. Anyway, the fact that the actual situation appears problematic should not be used s an excuse for not looking ahead. One of the most important government programs for numerous countries is that of "Brain Gain".

The initiative for establishing such a project in Albania came as a corollary of 20 years of "Brain Drain". The "Brain Drain" phenomenon occurs mostly in developing countries where individuals considered as the "Brain" of society immigrate to developed countries.

The OECD (Organization for Economic and Development Cooperation) member countries show a rate of $25-50 \%$ concerning the migration of qualified forces, a phenomenon that may lead to a cerebral hemorrhage in these countries.

This phenomenon is also noticed in countries of big investments such as Taiwan, Singapore, Malaysia, also in China and India, but in a considerable smaller percentage than those mentioned above.
The European Union, being afflicted with this syndrome decades ago, is aiming at repatriating the "Brain" that immigrated to the US.

\section{Historic dialectics of Brain Gain and it's social effects}

The concept of "Brain Brain" has gone through a far reaching evolution referring to its origin and particularly to the various strategies used by many Eastern European governments lately, mainly aiming at the reduction of this in phenomenon. Therefore, early studies concerning the immigration of qualified labor forces, which characterized the loss of specialized and skilled employees as the "Brain Drain" phenomenon, made room for new definitions.

Until the end of the Second World War, highly qualified migrants were very rare, and often not relevant in historical or cultural terms. Referring to this period, researchers dealt with a specific case, that of the German and Italian scientists who leaved their countries because of the Fascism and Nazism.

After the end of the war, the production processes and volume changed dramatically increasing the number and the economic importance of highly qualified migrants. This migration attracted the attention of researchers.

It was from 1960 up to 1970, that the new economic and political realities caused the inclusion of students, coming from poor countries and studying in developed countries, in this phenomenon.

This was the reason why the term of "reverse transfer of technology" was used by UNCTAD in the resolution 39III/1972. Two important milestones were settled here: the first making sure that those developing countries losing their potential had the right to take actions to decrease their loss and second, the rich countries had the obligation to compensate the developing countries for the loss of their potential. For this reason there was an incentive of an international tax for skilled workers living their countries.

In most cases migration did not happen for occupational reasons and this made the effects calculation even harder.

It was the publication of the paper by UNITAR with the Institute Card of Training and Research of United Nation in 1978 that changed entirely the theoretical international immigration frame of qualified employees. This study showed that most of those who left their countries, especially those most brilliant ones, turned back to their countries and continued to climb the social ladder, being part of highly qualified employee forces mainly in scientific sphere. Hence, "Brain Drain" was no longer a problem as developing countries had learned how to handle this phenomenon.

Beginning in the 80ies the massive internet use overthrew the concept of localism in academic contributions because everyone could work with others, regardless the location.

Another idea was that qualified people move to emerging economies, because by doing so their abilities become more useful, like in the cases of South West Asia and Poland. 


\section{THE ALBANIAN BRAIN DRAIN PHENOMENA AND THE BRAIN GAIN STRATEGY}

During recent years this phenomenon appeared again and has brought up many discussions.

Recently, this topic, received a wide interest mainly in areas as Latin America, the interest on doing research appears to shift towards Latin America and India.

The interest in these countries goes beyond a simple academic one regarding the factors that threaten their stock of human recourses in the fields of science and technology.

At the same time the changes in the Soviet Union and East Europe created a new wide field for research regarding these phenomena. The dissolution of the Warsaw Tractate turned Eastern European countries into research laboratories where researchers concluded with contradictory deduction. So instead of a "Brain Gain" there appeared a "Brain Waste" phenomenon, for very few emigrants from Eastern Europe were provided with good and qualified job positions in the countries they settled down.

For this purpose different researches worked on various studies e.g. Ledeniova, who examined the emigration rate among students in the Former Soviet Union (1995) or Grecist, who investigated the motivation of the Serbian scientist to live the country or origin.

However, as Salt stands, there is neither for the term "highly qualified" nor for the term "migration" a universal definition.

Therefore, in order to achieve a stable conclusion regarding these phenomena, we must base in statistic analyses, and for this purpose use a widely excepted definition of the term "highly qualified".

One possible definition is that of including the skilled blue and white collar workers in this category.

This definition is also very common, when it comes to migration studies in East Europe. People, who have a university degree or something similar, are included in one category and this category stands for "intellectuals, scientists and technicians".

At this point, it is time to underline the different shapes of migration, which depend on the professional background of migrants and the enrollment at the host country. We may put in evidence some tendencies of positive discriminated migration like the case of Australia, offering an incentive to a certain category of people to immigrate or the case of Indian doctors in UK. In both cases there are cultural and national connections between the immigrants and the host country. Anyway, the correlation between the investments and the industry in the host country, the availability of local resources, the expertise of the field there, and the emigrants category, education and professional background is quite evident.

Furthermore, it is necessary to make a distinction between the international mobility for research and development and the brain drain phenomena.

Many scientist, researcher and experts may leave their countries in order to broaden their knowledge and increase their expertise. Nonetheless, most countries who consider this as loss of qualitative human resources, do not offer any possibilities to those people to broaden their knowledge and professional abilities.

Nonetheless, the main concern in this whole research spiral was to unveil the most decisive factor, namely the cultural impact in the county of origin as well as in the country of destination. A very important component in order to measure the "Brain Drain", "Brain Waste" and of course the "Brain Gain" effect.
However, the discussion of this phenomenon is not e mere definition. Building a national strategy such as "Brain Gain", means having a clear vision of what this strategy bears and what it aims at ,as well as being aware of the "Brain Drain" category along with all it's elements that trigger and accompany it, those elements, who tend to come back.

It is important to be known the causes of migration and professional and academic evolution in the destination countries of this category. Thus, it can be foreseen and calculated the impact of their return in accordance with the true reasons of their return and the strategies used from government.

It's time for a distinction and a definition: Scientific contribution deriving from a scientific field attained and immerged in migration countries and the decision - making abilities on one side, and the leading and administrative abilities, which are naturally related to the economic, social, cultural frame and to the value systems of the origin countries, where these people are supposed to return, on the other side.

Scholars of this field make an important definition: the scientists "Brain Drain" requires first of all, the clear definition of the category on a national level in the countries of origin furthermore, the category has to be numerically perceptible compared to the general population number and there has to be a huge mass of people that decide to migrate, that huge that their departure would create a big vacuum to the respected category. On the contrary, it is the cause to focus on other types of categories concerning "Brain Drain", where Eastern European countries especially Albania has got a qualified and competent labor mass.

\section{Different prospective for Brain Gain and universities involvement}

The "Brain Gain" strategy applied in international and other institutional levels has always had an influence on the long-term development of universities.

Nevertheless, "Brain Gain" is not a strategy that is applied and studied only by developing countries or those countries that are recently affected from "Brain Drain" phenomenon. It has attracted the attention of many universities of developed countries, bringing new dimensions regarding the definition of these two phenomena

At the same time it has been propagated as salvation for university life in many Eastern European countries including Albania

\section{One case of Brain Gain in US}

In the USA "Brain Gain" is seen as a strategy to lead a certain category of people, who actually decided to become part of the working class but, who show a great potential for further development through studying, towards university life. Briefly, it is about increasing the access in teaching adults (i.e. Wisconsin case, USA, 2002). However, the success of the strategy in case at hand is based upon entirely clear and measurable objectives, the evaluations done directly and of course on the cost of its initiators and executives

Objectives like:

- Expanded opportunities for adult students to obtain a university diploma.

- Insertion of a helping mechanism for these students and for their time management problems

- More responsibility towards adult oriented programs 
- Increasing the standard of graduated students on state rather than on the federal level

At the same time appointments of activities like:

- Adult necessities analysis for university studies regarding time and place

- Creation of mixed courses and common programs.

- Studies in distance etc.

Also of great importance is to directly charge the involved institutions for their successful work or failure because such an approach assures the functionality of the strategy. Furthermore, the direct involvement of the strategy initiators and benefiters in obtaining and assuring the necessary resources for the interested parties leads to an increase of their responsibility towards the strategy success.

\section{Brain Gain in the Albanian prospective}

Albanian strategy case aims directly on having an impact on university life but with more general objectives, in macro level terms, not addressing clearly the interests of the project itself.

Some objectives of the applied strategy are:

- Substitution of old concepts with new ones.

- Development of new initiatives and strategies concerning universities management.

- Identification of individuals with an excellent scientific reputation for the development of the Albanian Science

- Creation of partnerships in the fields of scientific research teaching

The governmental financial support for the activities within the strategies enhances the credibility and access of those, but at the same time it makes people included in a "brain gain" category less responsible in this partnership. Furthermore, this support does not pursue the primarily effects that the strategy has had in universities affected by this phenomenon.

Anyway, what needs to be done is the distinction between the impact on the scientific development and that on the administrative and management life of public Albanian universities that are regulated by law. Also the appliance of the "Brain Gain" category in Albanian Universities happens in accordance with the laws of the country but not necessarily in accordance with the leading abilities and skills of the persons' involved.

The Contingent deficiencies in strategy projection and it's outcome evaluation are:

- lack of a quantitative evaluation e. g the number of those who migrated in the last 20 years

- lack of classification of the population in categories in terms of education and technical skills

- unknown dynamic of the migrated population in country of destination.

In other terms there is no credible evaluation of the target population with regard to the application of this strategy. Consequently, the measurements of the objectives and accomplishments are vaguer, which diminishes the chances for success and recognition for this strategy.

Brain Gain scenarios in Albania

The Albanian government is disseminating greatly the Brain Gain strategy. This is very positive, but it is better to be cautious because all that may remain from an ambitious project is a "nice speech"deviating from the project mission.

Will "The Brain" return to Albania?

It takes a more detailed analysis of the phenomenon, in order to prove that this theory is a successful one in a couple of years.

First: The phenomenon needs to be analyzed, in order to understand why people go abroad.

There is a list of reasons: lack of good working conditions, lack of good salary system, low evaluation of work in the country, lack of infrastructure in winning back "The Brain", lack of information concerning the institutions in the country etc.

Second: What contentment sense people working in the administration?

In order to make the strategy successful, it is of great importance that people working for the administration feel comfortable and enjoy their work, because only such people tend to stay in the country of origin.

Third: By now it is possible to prevent "Brain Drain".

All people who will decide to turn back to Albania are going to be confronted with the second moment mentioned above, before taking such a step. At the same time they face another essential moment, the moment of their adoption to the Albanian reality. Without knowing the Albanian reality by their return, they would become victims of negative elements, regardless their values. Thus, their reputation and values in respective fields would fade and that would lead not only to a devaluation concerning the project importance but would also harm the interests of the Albanian State (regardless the fact that this action may be set with intent).

Forth: Promotion and marketing of the repatriates.

It is necessary to have a marketing program regarding the return of the migrated brain. Nonetheless cautiousness is demanded to make sure that the human and scientific values of those repatriates, which prevailed in time, do not get harmed.

Let us try to put ourselves in those repatriates place - how would a repatriate feel returning after two years and not being respected at all (Glut theory) but just being noticed and evaluated because of their return. Everything needs to be in balance, caution has to be in firs place so that the return of 1, 2, 3 will not led to the departure of 100,200,300 others.

So that this program can work out and become a success it is essential that both the Albanian government and the repatriates respectively the potential repatriates, act by taking into consideration this rule: "Doing the right things in the proper way"

Through our actions we can bee willingly or unwillingly in one of the squares of the matrix below.

Lately the discussion regarding "Brain Gain" has brought forward a new term called "Brain Circulation". "Brain Circulation" stands for providing favorable terms regarding financial and communication issues to facilitate "Brain" migration from one country to another-be it for pat-time work or research work- and for providing comfortable working and living conditions for the "Brain" in the country of origin. Thus, the "Brain" will not intend to leave since the condition abroad will not (won't) bee any longer "the forbidden Fruit" and the "magnetic" effect of attracting people and !transforming migration into something very normal, is going to fade. 


\section{THE ALBANIAN BRAIN DRAIN PHENOMENA AND THE BRAIN GAIN STRATEGY}

Following the idea of "Brain Circulation" companies and institution from other countries would also be able to make use of the same high qualified intellectual source by indirectly avoiding the "Brain Drain" from developing countries toward developed countries.

\section{Conclusion}

The historical evolution of the "brain drain" and "brain gain "phenomena lead to a dynamic evolution on the scientific phenomena definition itself. At the same time, the research focus changed and it's still changing depending on the socio-economic evolution and interest. Thus, strategies to prevent "brain drain" effects and to enlarge "brain gain" must be developed in an wide international background and in a specific national notion as well. There must always be a large theoretical research and a primary and secondary data collection (a base line) regarding the phenomena development prior a national strategy set up. Thus, strategy itself will come out as an organic and logical output of those scientific and realistic premises.

Nevertheless, there is still space for recommendation without discriminating the intellectual values of the country working for "brain gain" through:

- Use the Balance Scorecard as a strategic management system in "brain gain" strategy set up and application in the case of Albania

- Use a stakeholder approach in objectives and aims of such program and strategy and their outcomes measurements

- Starting from a base line of the phenomena, target population evaluation, specification of benefits and beneficiaries to better support the application and account giving on the outcomes of such a program and strategy as well

- Adopting programs for the repatriates in order to avoid all illegal acts.

Performing repeated analyses and revising the "Brain Gain" project by focusing on the positive aspects of such a program.

\section{REFERENCES}

Ansoff, Declerck, Hayes, From Strategic Planning to Strategic Management, 1976

\section{BCG Matrix, The Boston Consulting Group, 1960}

Bernstain J.H \&Shuval. J.T, Occupational continuity and change among immigrants physicians from Soviet Union to Israel, International Migration, 1995

Boussaid Lejla, L'exode de cerveaux et le pays en development, migration Societe, Avril 1998

Franchovich L, Some notes on the roles and behaviors of qualified migrants from ex- Jugoslavia Etudes Migrations, 2000

Freeman,Strategic Management: A stakeholder approach, 1984

Gaillard A.M \& Gaillard J, Les enjeux des migrations ssientifique internationals. De la quete savoir ala circulation des competences, 1999

Grecists, Migration of scientists and professionals from the republic of Serbia, studi Emigrazione, 1995

Hill \& Joans, Strategic Management: An integrated approach, 2006

Huges. S.H, La grande migrazione intellettuale, 1970

Irdale R, The need to import skill personnel, factor favouring the hindering it's international mobility, International migration, 1999

Kaplan\& Norton, Using the Balance Scorecard as a strategic management system, Harvard Business Review, 1996
Ledeniova L, Attitude to emigration among university students in the former USSR, 1995

Mahoney \& Pandian, The resource based view within the conversation of the Strategic Management, Strategic Managemnet Journal, 1992

Oecd, Manual of human resources devoted to science and technology, Oecd, 1995

Pattannyak, Human Resource Management, 2005

Programi I Qeverise se Shqiperise, Brain Gain, 2006

Royal Society, Emigrations of scientists from the United Kingdom, a report of a committee appointed by the council of the Royal Society, 1963

Salt J, International movements of the highly skilled, OCDE, International Migration Unit, 1997

Salt J \& Singleton A, A comparison of the labor force survey and regulation, 1993

Salt $\mathrm{J}$ \& Singleton $\mathrm{A}$, Thee international migration of expertise: the case of the united Kingdom, 1995

Storey, Human Resource Management: A critical text, 1995

Todisco E, Mobilit? dei cervelli e mobilit? delle coscienze, Atti del Convegno Internazionale Migrazioni, scenari per il XXI secolo, Sezione di Firenze, 2000

UNCTAD, Development Aspect of the Reverse Transfer of Technology, UNCTAD Secretariat, 1978

UNESCO, Statistical Handbook, 1999 